\title{
Triclosan exposure results in alterations of thyroid hormone status and retarded early development and metamorphosis in Cyprinodon variegatus
}

\author{
Joseph G. Schnitzler ${ }^{\mathrm{a}, *, 1}$, Bruno Frédérich ${ }^{\mathrm{b}}$, Mélanie Dussenne ${ }^{\mathrm{a}}$, Peter H.M. Klaren ${ }^{\mathrm{c}}$, \\ Frédéric Silvestre ${ }^{\mathrm{d}}$, Krishna Das ${ }^{\mathrm{a}}$ \\ a Laboratory of Oceanology, MARE, B6c, Liège University, Liège, Belgium \\ ${ }^{\mathrm{b}}$ Laboratoire de Morphologie Fonctionnelle et Evolutive, AFFISH Research Center, Liège University, Liège, Belgium \\ ${ }^{\mathrm{c}}$ Department of Animal Ecology and Physiology, Institute for Water and Wetland Research, Faculty of Science, Radboud University, Nijmegen, The \\ Netherlands \\ ${ }^{\mathrm{d}}$ Laboratory of Evolutionary and Adaptive Physiology-URBE, UNamur, B-5000 Namur, Belgium
}

\section{A R T I C L E I N F O}

\section{Article history:}

Received 4 July 2016

Received in revised form 10 October 2016

Accepted 22 October 2016

Available online 24 October 2016

\section{Keywords:}

Sheepshead minnow

Development

Triclosan

Thyroid hormone

Morphometrics

\begin{abstract}
A B S T R A C T
Thyroid hormones are critically involved in somatic growth, development and metamorphosis of vertebrates. The structural similarity between thyroid hormones and triclosan, an antimicrobial compound widely employed in consumer personal care products, suggests triclosan can have adverse effects on the thyroid system. The sheepshead minnow, Cyprinodon variegatus, is now used in ecotoxicological studies that have recently begun to focus on potential disruption of the thyroid axis by endocrine disrupting compounds. Here, we investigate the in vivo effects of exposure to triclosan $\left(20,50\right.$, and $\left.100 \mu \mathrm{g} \mathrm{L}^{-1}\right)$ on the thyroid system and the embryonic and larval development of $C$. variegatus. Triclosan exposure did not affect hatching success, but delayed hatching time by $6-13 \mathrm{~h}$ compared to control embryos. Triclosan exposure affected the ontogenetic variations of whole body thyroid hormone concentrations during the larval phase. The T3 peak around 12-15 dph, described to be indicative for the metamorphosis climax in C. variegatus, was absent in triclosan-exposed larvae. Triclosan exposure did not produce any deformity or allometric repatterning, but a delayed development of 18-32 h was observed. We conclude that the triclosan-induced disruption of the thyroid system delays in vivo the start of metamorphosis in our experimental model. We observed a global developmental delay of $24-45 \mathrm{~h}$, equivalent to 4-7\% prolongation of the developmental time in $C$. variegatus. The costs of delayed metamorphosis can lead to reduction of juvenile fitness and could be a determining factor in the outcome of competitive interactions.
\end{abstract}

(c) 2016 Elsevier B.V. All rights reserved.

\section{Introduction}

Numerous chemicals present in aquatic environments affect thyroid hormone synthesis, transport, cellular uptake and metabolism and can ultimately disrupt thyroid homeostasis (Boas et al., 2006; Brown et al., 2004). Among these is triclosan (5chloro-2-(2,4-dichlorophenoxy)phenol), a synthetic chlorinated

\footnotetext{
* Corresponding author.

E-mail addresses: joseph.schnitzler@ulg.ac.be (J.G. Schnitzler) bruno.frederich@ulg.ac.be (B. Frédérich), melanie_dussenne@hotmail.fr (M. Dussenne), p.klaren@science.ru.nl (P.H.M. Klaren), frederic.silvestre@unamur.be (F. Silvestre), krishna.das@ulg.ac.be (K. Das).

1 Current address: Institute for Terrestrial and Aquatic Wildlife Research, University of Veterinary Medicine Hannover, Foundation, Büsum, Schleswig-Holstein, Germany.
}

phenoxyphenolic compound with a generalized use as an antimicrobial and preservative in many personal care and household products (Bedoux et al., 2011; Dann and Hontela, 2011; Fang et al., 2010). Currently, widespread contamination with triclosan has been detected in aquatic ecosystems of several countries (Bedoux et al., 2011; Dann and Hontela, 2011; Fang et al., 2010). Triclosan is commonly measured in various environments and it is detected in the majority of US rivers, making this one of the most frequently encountered organic contaminants (Kolpin et al., 2002). The structural similarity between triclosan and thyroid hormones (Dann and Hontela, 2011) suggests it can have adverse effects on the thyroid system. Toxic effects of triclosan have been reported in aquatic organisms (Bedoux et al., 2011; Dann and Hontela, 2011; Fang et al., 2010). However, little is known about the mechanisms by which triclosan disrupts the thyroid axis. 
In teleost fishes, thyroid hormones (THs) are involved in many physiological processes such as growth, pigmentation and the development of cardiovascular, digestive and muscular systems (Blanton and Specker, 2007; Power et al., 2001). Metamorphosis, i.e. the transition from larval to juvenile stage, is also regulated by THs (McMenamin and Parichy, 2013; Paris and Laudet, 2008; Power et al., 2001) and involves morphological, physiological and behavioural changes (Dufour et al., 2012) The mechanisms and genes involved have still not yet been fully elucidated but it has been hypothesized that a disruption of thyroid system influences the fish metamorphosis, and thus the viability of larvae (Power et al., 2001). These early developmental stages might be the most sensitive to environmental toxicants that target the thyroid axis.

Landmark-based geometric morphometric methods (Bookstein, 1997; Rohlf and Marcus, 1993; Zelditch et al., 2012) provide valuable tools to analyse variations of shape and size during ontogeny. Conceptually, the pattern of ontogenetic shape changes can be described by the trajectory of an organism in the shape space plus the rate at which it proceeds along the trajectory (Klingenberg and McIntyre, 1998) (Fig. 1). In an ecotoxicological context, some pollutants can induce developmental and morphological divergence among organisms as a result from the directional change in the trajectories of shape changes (i.e. ontogenetic repatterning), in the duration or in the rate of development (Webster and Zelditch, 2005) (Fig. 1).

The sheepshead minnow Cyprinodon variegatus is widely used in ecotoxicological studies that have only recently begun to focus on potential disruption of the thyroid axis by xenobiotics and endocrine disrupting compounds. The present study aims to quantify the effects of exposure to triclosan on C. variegatus during embryonic and larval development. First, we investigated several parameters of embryonic development such as fertility ratio, hatch ratio, and timing of hatching. Secondly, we determined if and how triclosan affects ontogenetic variation of thyroid hormones in developing larvae. Thirdly, knowing that thyroid hormones are involved in somatic growth and metamorphosis, we tested the hypothesis that triclosan alters the pattern of ontogenetic shape changes (i.e. ontogenetic trajectory, rate of shape variation) using geometric morphometrics. Using these combined approaches, we illustrate in C. variegatus that triclosan exposure alters THs concentrations, and induces a delay of development and metamorphosis without ontogenetic repatterning.

\section{Materials and methods}

\subsection{Animals, fertility ratio, hatch ratio and hatching delays}

Adult C. variegatus were purchased from Aquatic Research Organisms (ARO Inc. New Hampshire, USA) in April 2013. Males and females were maintained in 150-L glass aquaria in aerated, filtered seawater at a salinity of $20 \pm 1$, temperature at $26 \pm 1{ }^{\circ} \mathrm{C}$, at a photoperiod of $14 \mathrm{~h}: 10 \mathrm{~h}(\mathrm{~L}: \mathrm{D})$ and fed daily with brine shrimp (Artemia nauplii) and flake food (Sera Vipan).

Groups of 2 males and 3 females were paired in 5 spawning tanks with dimensions (length $\times$ width $\times$ height) of the main body measuring $350 \mathrm{~mm} \times 250 \mathrm{~mm} \times 200 \mathrm{~mm}$ for $2 \mathrm{~h}$ (Cripe et al., 2009) during 10 breeding sessions. Embryos were collected from spawning tanks. Approximately 2000 undamaged embryos were selected using a dissection microscope and randomly assigned to each of four treatment groups: Control, 20, 50 and $100 \mu \mathrm{g} \mathrm{L}^{-1}$ triclosan (Irgasan $>97 \%$, Sigma-Aldrich). Among these, three breeding sessions including 522 eggs in total were especially selected to evaluate hatching rhythms and the influence of the experimental treatments. These embryos were placed in 24-well plates with $1 \mathrm{~mL}$ volume of test solution to follow the individual evolution of each embryo ( 3 replicate breeding sessions, with two replicate well plates per treatment). The plates were placed in an incubator (BCR25, Jiangsu Best Electrics Co., Ltd) at $26^{\circ} \mathrm{C}$ and the test solutions were refreshed daily to avoid oxygen deficiency. The number of newly hatched larvae was registered every hour from $91 \mathrm{~h}$ postfertilization (hpf) until $163 \mathrm{hpf}$. At the end of the experiment, the total number of hatched larvae was recorded in order to calculate the hatching ratio. The other eggs (ca. 1450 from 7 breeding sessions) were placed in petri dishes with $50 \mathrm{~mL}$ working volume per and incubated in groups of 50 embryos in an incubator (BCR25, Jiangsu Best Electrics Co., Ltd) at $26^{\circ} \mathrm{C}$. Incubation media were changed every $24 \mathrm{~h}$ and the number of dead embryos and live fry were recorded in order to calculate the fertility and hatch ratios. After 6 days, the embryos hatched and larvae were transferred to a glass tank (1 L working volume, 50 larvae per tank).

Larval density and feeding rate were controlled and identical for each exposure group. From day 0 post-hatch (dph), larvae were fed with cultured brine shrimp. We refreshed $100 \%$ of the medium every 3 days for all exposure conditions in order to maintain a constant exposure load and to avoid water quality degradation by excess food and excrements. The concentration of triclosan in water was analysed using a commercial Abraxis Triclosan Assay kit purchased from Abraxis LLC (Warminster, USA). The Abraxis Triclosan Assay is an immunosorbent enzyme-linked assay (ELISA) designed for the quantification of triclosan and methyl triclosan. The triclosan concentrations in our experimental media were analysed when freshly prepared and immediately prior to renewal at five occasions during the experimental period (Supplementary material Table 1). The measured concentrations remained within $80-120 \%$ of the nominal concentrations, so that the effect concentration can be expressed relative to the nominal concentration according to the OECD Guidelines for testing chemicals (OECD, 2013).

Juvenile fish were netted, and rapidly euthanized in overdose of MS222 (500 $\left.\mathrm{mg} \mathrm{L}^{-1}\right)$ at 9, 12, 15, 18 and $21 \mathrm{dph}$ and randomly assigned either to thyroid hormone (round 1200 individuals from five replicate breeding sessions) or to geometric morphometric analysis (250 individuals from three replicate breeding sessions).

\subsection{Thyroid hormone extraction and analysis}

Whole body concentrations of thyroid hormones show a typical pattern during the metamorphosis of teleost fishes, indicating that the ontogeny of thyroid hormones is related to specific morphological characteristics that represent early development (Chang et al., 2012; Crane et al., 2004; de Jesus and Hirano, 1992; Johns et al., 2009; Kawakami et al., 2003; Klaren et al., 2008; Shiao et al., 2008; Szisch et al., 2005; Yamano, 2005). In C. variegatus, metamorphosis is associated with increases in thyroid hormone levels around 9 and 18 days post hatching (Schnitzler et al., 2015). Samples of 10-20 larvae were placed in preweighed $1.5-\mathrm{mL}$ microfuge tubes, and wet weights recorded prior to snap-freezing on dry ice and storage at $-80^{\circ} \mathrm{C}$. Larval samples were dried at $60{ }^{\circ} \mathrm{C}$ to constant dry weight (d.w.). Thyroid hormones were extracted as described by Tagawa and Hirano (1987). Samples (0.01 g larval d.w.) were homogenized in $2.6 \mathrm{~mL}$ ice-cold 99:1 (vol./vol.) methanol:ammonia containing $1 \mathrm{mM}$ of the iodothyronine deiodinase type-1 inhibitor 6- $n$-propyl-2-thiouracil (PTU). Homogenate and extraction medium were thoroughly mixed for $10 \mathrm{~min}$ at $4{ }^{\circ} \mathrm{C}$, and then centrifuged at $2000 \mathrm{xg}\left(15 \mathrm{~min}, 4^{\circ} \mathrm{C}\right)$. This procedure was repeated twice, supernatants were pooled and lyophilized. The residue was resuspended in $875 \mu \mathrm{L}$ of a $6: 1$ vol./vol. mixture of chloroform and 99:1 methanol:ammonia including $1 \mathrm{mM}$ PTU, and $125 \mu \mathrm{L}$ barbital buffer ( $50 \mathrm{mM}$ sodium barbitone in distilled water, at $\mathrm{pH} 8.6$ ). Samples were mixed for $10 \mathrm{~min}$ at room temperature. The upper phase was aspirated and lyophilized at $45^{\circ} \mathrm{C}$. Residues were redissolved in $60 \mu \mathrm{L}$ barbital buffer contain- 

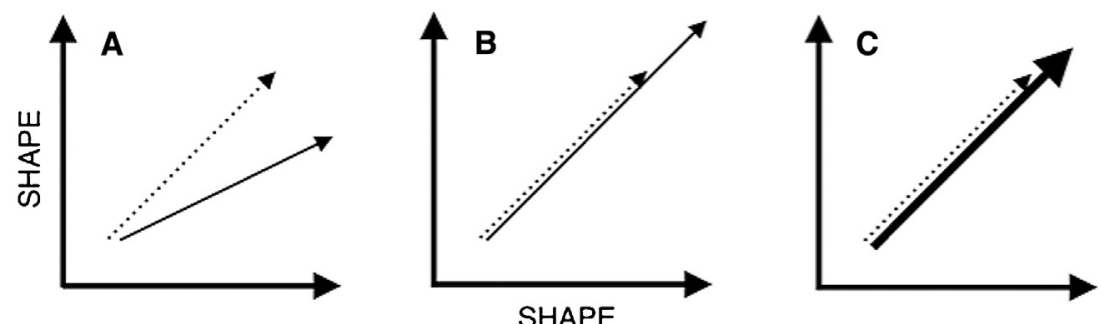

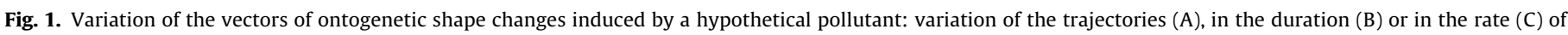
development. The vector of control group is represented by dotted line when the straight black line illustrates the group exposed to the pollutant.

ing $0.1 \%$ bovine serum albumin. Aliquots of 25 and $50 \mu \mathrm{L}$ were taken for T4 and T3 analysis, respectively. Total T4 (tT4) and T3 (tT3) concentrations in the extracts were measured in duplicate with a competitive ELISA (DIAsource ImmunoAssays S.A., Louvain-la-Neuve, Belgium) according to manufacturer's instructions. Calibrators were prepared in the same barbital buffer matrix as the samples. A 4-parameter logistic calibration curve was calculated with the immunoassay software Gen5. The intra-assay and inter-assay coefficients of variation for the tT4 and tT3 ELISA reported by the manufacturer are $6.4 \%$ and $9.9 \%$, and $4.1 \%$ and $9.0 \%$, respectively. The reported cross reactivity of the ovine antiT4 antibody to d-T4 is $94 \%$ (the reactivity to $1-\mathrm{T} 4$ is set at $100 \%$ as a reference), and to $1-\mathrm{T} 3$ and $\mathrm{d}-\mathrm{T} 3$ is $3.3 \%$ and $1.8 \%$, respectively. The reported cross reactivity of the ovine anti-T3 antibody to l-T4 is $<0.1 \%$ (setting the reactivity to $1-\mathrm{T} 3$ at $100 \%$ ). Crossreactivities of both antibodies to diiodothyronine, diiodotyrosine and iodotyrosine are $<0.1 \%$. The reported sensitivities of the tT4 and tT3 ELISA are $6 \mathrm{ng} \mathrm{mL} \mathrm{m}^{-1} \mathrm{~T} 4$ and $1.6 \mathrm{ng} \mathrm{mL}^{-1} \mathrm{~T} 3$, respectively.

\subsection{Developmental stages}

Individual larvae were staged using a developmental table described previously (Schnitzler et al., 2016). Briefly, this table describes the development of $C$. variegatus in 15 stages, with emphases on external traits such as fin ray morphology and the development of pigmentation. These traits could be easily assessed with standard laboratory equipment such as stereomicroscope.

\subsection{Geometric morphometrics}

Fish were immersed in a solution of $1 \%$ methylcellulose, aiding to position the specimen in a stable lateral view. Individuals were photographed using a Zeiss dissecting microscope Stemi 2000-C, a MOC-510 Müller ${ }^{\circledR}$ camera (5 MP) and associated image acquisition software SI-Capture 3.6. A millimetre scale was placed in the background of every specimen for size reference. Specimens were placed in lateral view with their dorsal and anal fins extended.

We quantified shape variation using landmark-based geometric morphometric methods (Bookstein, 1996, 1997; Rohlf and Marcus, 1993). An extensive introduction to applications of geometric morphometrics in biology is available elsewhere (Lawing and Polly, 2010; Zelditch et al., 2012). A geometric morphometric analysis involves a series of steps which are briefly described here. The Cartesian coordinates of a configuration of anatomical landmarks capture the form of an organism. Here, we used 11 landmarks (LMs) and 74 semilandmarks (SLMs) to describe the overall body shape of C. variegatus larvae and juveniles (Fig. 2 \& Supplementary material Table 2). After the removal of variation in orientation, position, and size, a "pure" shape can be analysed. This was achieved by optimally superimposing landmark configurations using a process called generalized Procrustes analysis (GPA) (Rohlf and Slice, 1990). During

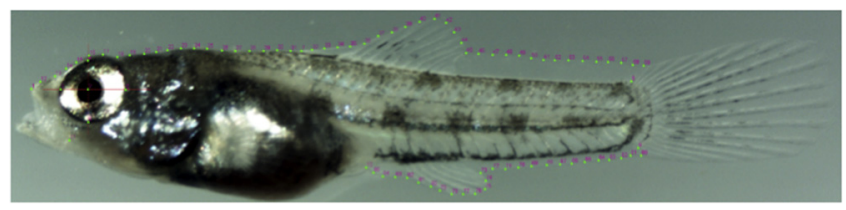

Fig. 2. Positioning of landmarks along the shape of a $21 \mathrm{dph}$ control larva.

this superimposition, a consensus configuration (average) of landmarks is calculated and will be used as reference. Centroid size (CS) is the measure of the dispersion of landmarks around their centroid and is computed as the square root of the sum of squared distances of all landmarks from the centroid (Bookstein, 1997). Partial warp scores (PW) including both uniform and non-uniform components were calculated and used as descriptors of shape variation (Bookstein, 1997; Rohlf and Marcus, 1993).

The ontogenetic pattern of shape variation was calculated by multivariate regressions of PW scores on log-transformed CS, time or developmental stage using Regress8 (IMP softwares) (Sheets, 2014). In order to test whether triclosan alters the patterns "shape vs size", "shape vs time" or "shape $v s$ developmental stage" (i.e. variation of the direction where ontogenetic vectors are pointing in the morphospace; Fig. 1), we compared the angle among group-specific multivariate regression vectors using VecCompare8 implemented in Regress8. An elaborate explanation of this approach is provided elsewhere (Zelditch et al., 2004). Briefly, in the context of this study, a within-group vector (i.e. Control, $20 \mu \mathrm{g} \mathrm{L}^{-1}$ triclosan, $50 \mu \mathrm{g} \mathrm{L}^{-1}$ triclosan or $100 \mu \mathrm{gL}^{-1}$ triclosan) is composed of all regression coefficients of the shape variables (PW) and the independent variable (i.e. log-CS, time or developmental stage). The range of angles between such vectors within each group is calculated using a bootstrapping procedure $(N=400)$. This range was then compared with the angle between the vectors of groups. If the between-group angle exceeds the 95\% range of the bootstrapped within-group angles, the between-group angle is considered as significantly different, and thus the ontogenetic trajectories are different.

The rate of change in the overall shape was estimated using the Procrustes distance (PD) (Bookstein, 1996). The PD was used as a univariate measure of shape difference but needs to be considered as an overall measure of multivariate shape components. Dynamics of shape changes are visualized by plots of PD between each specimen and the consensus shape of each group on CS, time or developmental stage. Moreover, this dynamic of shape changes was approximate by a polynomial regression analysis for every treatment groups.

To compare the extent of shape changes in every group, the length of their ontogenetic trajectories was used. These lengths were calculated by the PD between the average shape at $9 \mathrm{dph}$ and at $21 \mathrm{dph}$. Confidence intervals are placed on these lengths by a bootstrapping procedure $(\mathrm{N}=400)$. 


\subsection{Statistical tests}

All data were tested for normality and presented as means \pm standard deviation. Except for morphometrics, statistical analyses were performed using $\mathrm{R}$ (version 3.1.1) ( $\mathrm{R}$ Development Core Team, 2014). All data were tested for normality. Kruskall-Wallis one-way analysis of variance on ranks was used with nonparametric multiple comparisons for each pair using Wilcoxon methods. A Kaplan-Meier survival curve analysis was performed to estimate the probability to hatch in function of the hours post fertilization. Statistical significance was accepted at $p<0.05$.

\subsection{Ethics statement}

All experimental procedures were approved by the University of Liège Institutional Animal Care and Use Committee (\#LA1610430).

\section{Results}

\subsection{Fertility ratio, hatch ratio and hatching delays}

Each spawning female produced 15 to 30 embryos per spawn; fertilization being assessed $24 \mathrm{~h}$ after spawning by counting the number of opaque (alive) and white (dead) embryos. Fertilization ratios were variable $(60.5 \pm 17.3 \%)$. They varied between reproduction sessions (Kruskal Wallis $\mathrm{H}=25.74 ; \mathrm{df}=5 ; p<0.01$ ) but not between the different triclosan exposure conditions (Kruskal Wallis $\mathrm{H}=0.06 ; \mathrm{df}=3 ; p=0.99$ ). The hatching ratios after an incubation time of 6 days were high $(84.2 \pm 10.1 \%)$. No difference between reproduction sessions (Kruskal Wallis $\mathrm{H}=7.01$; $\mathrm{df}=5 ; p=0.22$ ) or exposure conditions (Kruskal Wallis $\mathrm{H}=0.44$; $\mathrm{df}=3 ; p=0.93$ ) was observed.

The monitoring of hatching time began $91 \mathrm{~h}$ post-fertilization (hpf). A complete hatching process took 2-3 days. Kaplan-Meier survival curves adequately described the probability of hatching vs. hpf (Fig. 3). Hatching was affected by daylight, i.e.; hatch ratio was higher during light phase compared to the dark phase. KaplanMeier curves revealed significant differences among exposure conditions (Kruskal Wallis $\mathrm{H}=31.7 ; \mathrm{df}=3 ; p<0.01$; Supplementary material Table 3 ). Control larvae hatch earlier than triclosanexposed larvae. We observed a mean hatch time of $120 \mathrm{hpf}$ for unexposed embryos, it increased to 126-133 hpf for triclosanexposed embryos.

\subsection{Variation of thyroid hormone concentrations}

Whole body total TH concentrations were measured at 9, 12, 15 and $18 \mathrm{dph}$. The tT4 concentrations varied significantly over time in every condition (Kruskal Wallis $p<0.05$ ) (Fig. 4A). The control larvae showed a gradual decline in the tT4 concentration. T4 concentrations increased up to $15 \mathrm{dph}$ in triclosan-exposed larvae. For the control and $20 \mu \mathrm{g} \mathrm{L}^{-1}$ groups, we observed a peak of tT3 at 12 and $15 \mathrm{dph}$, respectively (Kruskal Wallis $p<0.05$; with effect sizes $d>0.46$ and $d>0.59$ respectively; Fig. 4 A). No significant variation of tT3 was observed in the groups exposed to concentrations of $50 \mu \mathrm{g} \mathrm{L}^{-1}$ or $100 \mu \mathrm{g} \mathrm{L}^{-1}$ triclosan (Kruskal Wallis $p>0.05$ ) (Fig. 4A).

Whole body tT4 concentrations varied significantly among exposure conditions at 9 and 15 dph (Kruskal Wallis $p<0.05$ ), whereas no differences were detected for 12 and $18 \mathrm{dph}$ (Kruskal Wallis $p>0.05$; Fig. 4B). The tT3 concentrations varied significantly among exposure conditions at $12 \mathrm{dph}$ (Kruskal Wallis $\mathrm{H}=8.7$; $\mathrm{df}=3$; $p=0.03$ ), whereas no differences were detected for 9,15 and $18 \mathrm{dph}$ (Kruskal Wallis $p>0.05$; Fig. 4B).

\subsection{Growth and morphological variation}

The dry weight of larvae increased significantly throughout post-hatch development time (Spearman $\mathrm{R}^{2}=0.83, p<0.01$ ). A significant difference between exposure conditions was only observed at $15 \mathrm{dph}$ (Kruskal Wallis $\mathrm{H}=10.8, \mathrm{df}=4, p=0.01$ ) (Supplementary material Fig. 6), the larvae exposed to $100 \mu \mathrm{g} \mathrm{L}^{-1}$ triclosan being significantly bigger than the control larvae (Wilcoxon $Z=3.21$, $p=0.01$.

All control and triclosan-exposed larvae showed significant differences in developmental stages over time (Spearman $\mathrm{R}^{2}=0.77$, $p<0.01$ ), indicating that the larvae move through their developmental stages during larval growth. Dorsal and anal fin development can be seen as a key event during metamorphic climax. No significant difference between exposure conditions were apparent (Kruskal Wallis $\mathrm{H}=0.43, \mathrm{df}=3, p=0.93$ ).

\subsection{Ontogenetic shape variation}

The growth of $C$. variegatus was highly and significantly allometric (Supplementary material Table 4). Results of a Goodall test are consistent with a linear relation between centroid size (CS) and shape (PW scores) during the whole ontogenetic dataset (Supplementary material Table 4). 29 to $37 \%$ of shape variance was explained by growth (Supplementary material Table 4), indicating that some variability in shape was possibly due to other factors than size.

To test whether triclosan modifies the trajectories of shape variation in morphospace, we compared the orientation of ontogenetic vector of the four treatment groups. The variance of within-group angle was higher than the angle between groups (Supplementary material Table 5). Thus, the angles between multivariate regression vectors were not significantly different and consequently, the null hypothesis of an identical direction of the ontogenetic vectors could not be rejected. A visual exploration of shape variation between 9 and $21 \mathrm{dph}$ in the control condition and triclosan-exposed larvae confirmed our previous results from the analysis of angles. Indeed, ontogenetic shape changes were highly similar among treatment groups (Supplementary material Fig. 7). Shape variation mainly concerns the development of dorsal and anal fins and the reduction of anal region (LM 10).

The length of ontogenetic trajectories differs among groups (Supplementary material Fig. 8). Control group show longer trajectories than triclosan-exposed groups. In other words, the extent of shape change was larger for the control group during the studied period (i.e. from 9 to $21 \mathrm{dph}$ ). The length of the ontogenetic vector of the $100 \mu \mathrm{g} \mathrm{L}^{-1}$ triclosan condition was significantly shorter than the vector of the control larvae. The variation of ontogenetic vector lengths among conditions was not explained by a growth difference as no significant difference in size (CS) was observed at 21 dph among groups $\left(F_{3,39}=0.42, p=0.74\right)$.

As suggested by polynomial regression analysis, the dynamics of shape changes could be divided in two phases (Fig. 5A \& B). The first phase expresses a relatively constant and slow rate of shape variation before reaching the consensus form of the ontogenetic data set (i.e. the inflection point of the polynomial model). The second phase was characterized by higher shape changing dynamics. In the control condition, the inflection point was reached earlier than in triclosan-exposed conditions (Supplementary material Table 6). This delay was represented by a size difference of 0.3-0.6 CS units or a time delay of around 18 to $32 \mathrm{~h}$. Consequently, the triclosanexposed larvae began the second phase of shape variation later than in controls. However, during this second phase, a higher dynamics of shape changes in triclosan-exposed larvae allowed control and triclosan-exposed larvae to reach similar shape. 


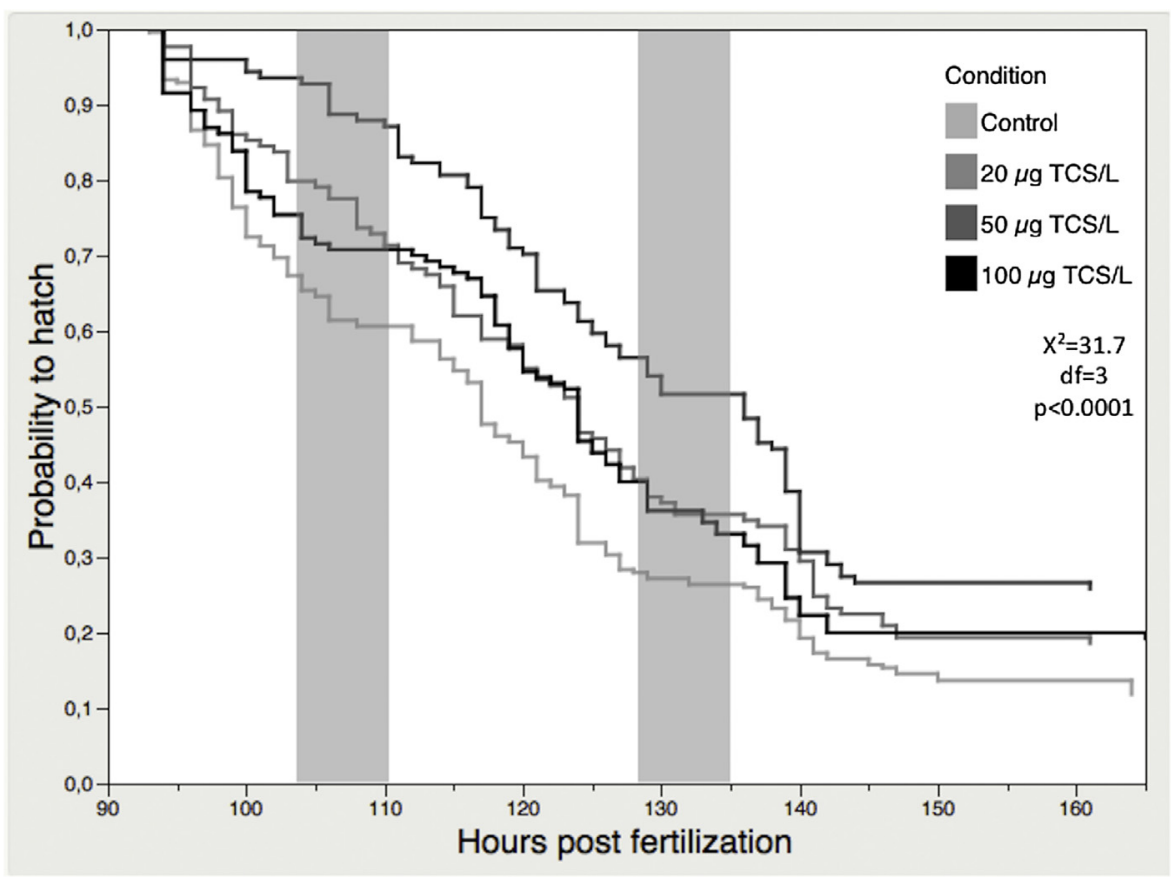

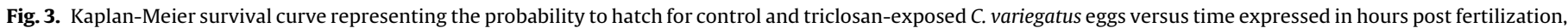
the shaded areas correspond to the dark phases.

\section{Discussion}

Exposure to environmentally relevant triclosan concentrations $\left(20,50\right.$ or $\left.100 \mu \mathrm{g} \mathrm{L}^{-1}\right)$ did not affect hatching success in C. variegatus but it delayed hatching time. We showed that triclosan exposure affects the ontogenetic variations of whole body thyroid hormone concentrations during the three first weeks of development in $C$. variegatus. Triclosan exposure did not result in any deformities or malformations of the juvenile but a delay of development was observed.

\subsection{Effects of triclosan during the embryonic phase}

Our data revealed clear circadian rhythms in C. variegatus with higher hatching percentage during daytime, as observed in Salmo salar (Brännäs, 1987) and Danio rerio (Villamizar et al., 2013). The timing of hatching is probably determined by the interaction between the developmental stage and the circadian rhythm. The embryos that have not reached the adequate stage of development during daytime wait until the next light period to hatch (Villamizar et al., 2013).

Exposure of eggs to concentrations of 20,50 and $100 \mu \mathrm{g}$ triclosan $\mathrm{L}^{-1}$ does not have any negative effect on the fertilization and hatching ratio in $C$. variegatus. However, triclosan exposure induced a delay of mean hatch time of around 6 to $13 \mathrm{~h}$ compared to control embryos. Orvos et al. (2002) observed no adverse effects of triclosan on hatch ratios in the rainbow trout (Oncorhynchus mykiss) for concentrations up to $71.3 \mu \mathrm{g} \mathrm{L}^{-1}$ (Orvos et al., 2002). On the other hand, various studies reported negative effects of triclosan on egg survival but the concentrations used in these studies were 3 to 7 times higher than in the present study. For example, Ishibashi et al. (2004) reported a significantly delayed and reduced hatching ratio of medaka (Oryzias latipes) exposed to $313 \mu \mathrm{g} \mathrm{L}^{-1}$ triclosan (Ishibashi et al., 2004). Similarly, eggs of Danio rerio exposed to $500 \mu \mathrm{g} \mathrm{L}^{-1}$ triclosan had a hatching time delayed from $48 \mathrm{~h}$ to $72 \mathrm{~h}$ (Oliveira et al., 2009).
The hatching process is dependent on osmotic, chemical and mechanical factors (Nassef et al., 2010). Some authors speculated that delayed hatching may be related to a reduced chorionase activity, the enzyme responsible for chorion digestion, that will result in an impaired capacity of the larvae to break the egg (Hallare et al., 2006). The structural similarity between triclosan and thyroid hormones suggests it can have adverse effects on the thyroid system (Dann and Hontela, 2011). Consequently, the delayed hatching time of the exposed larvae could be caused by a disrupted metabolism of maternal thyroid hormones contained in the yolk sac, or a decrease in volume of yolk sac (Nassef et al., 2010).

\subsection{Effect of triclosan on variation of thyroid hormones in developing larvae}

We have evaluated the effect of triclosan exposure on TH levels between 9 and $18 \mathrm{dph}$, i.e. the metamorphosis period (Schnitzler et al., 2015). The dynamic of TH concentrations in our control conditions followed the trend described by Schnitzler et al. (2015). While TH levels were constant in pre-metamorphosis stage of $C$. variegatus larvae, we observed that whole body total T4 levels begin to decrease at day $12 \mathrm{dph}$ to reach minimum levels at $21 \mathrm{dph}$. Total T3 levels increased to reach a peak at $12 \mathrm{dph}$ and decreased to pre-metamorphosis levels at $21 \mathrm{dph}$. Meanwhile, the molar T3:T4 ratio increases throughout that period, revealing an increase of the conversion rate of $\mathrm{T} 4$ to $\mathrm{T} 3$ in peripheral tissues by the action of deiodinase enzymes (Leatherland, 1982). Triclosan-exposed larvae showed quite a different pattern. The T4 concentrations increased up to $15 \mathrm{dph}$ while no variation could be observed either for T3 concentrations or for the molar T3:T4 ratio. The T3 peak around 12-15 dph that has been described as indicative for the metamorphosis climax in C. variegatus (Schnitzler et al., 2015) is absent in triclosan-exposed larvae.

The modes of action of triclosan on the thyroid function are largely unknown and the compound could have multiple targets in the thyroid system. The regulation of thyroid hormone bioavail- 

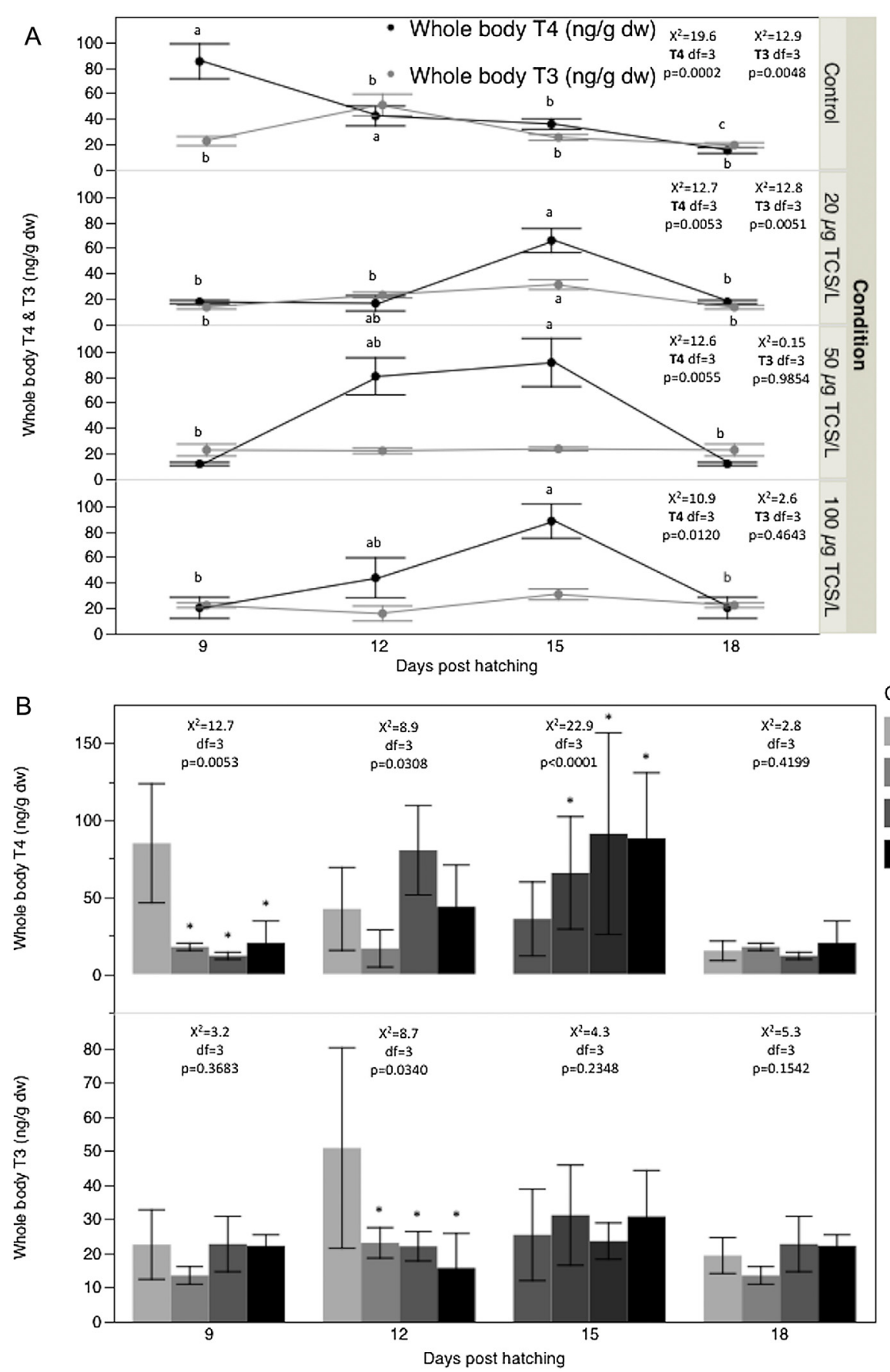

Condition

Control

$20 \mu \mathrm{g} \mathrm{TCS} / \mathrm{L}$

$50 \mu \mathrm{g}$ TCS $/ \mathrm{L}$

$100 \mu \mathrm{g} \mathrm{TCS} / \mathrm{L}$

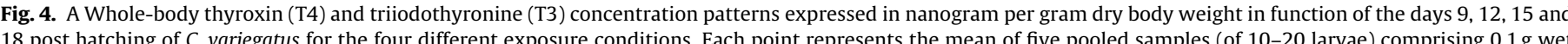

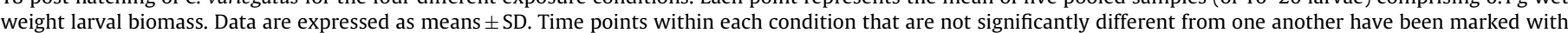

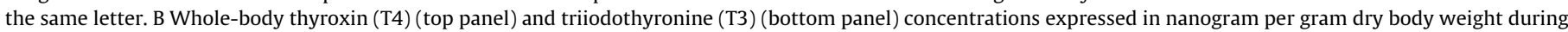

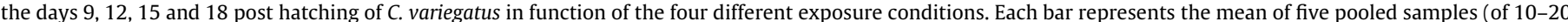

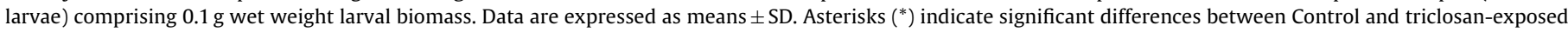
larvae.

ability in tissues and cells involves a complex and unique web of feedback systems (Zoeller et al., 2007). In teleosts and other vertebrates, the thyroid system involves two major components. First, thyroxine (T4) biosynthesis and secretion are largely under central control by the brain-pituitary-thyroid axis (Bernier et al., 2009). Second, the enzymatic conversion of T4 to its biologically active form 3,5,3-triiodothyronine (T3) by the action of deiodinases and their metabolism and receptor-mediated actions is largely under peripheral control in extra-thyroidal tissues (Eales and Brown, 1993). To the best of our knowledge, only one study has evaluated the effects of triclosan on the thyroid system of teleosts. Pinto et al. (2013) demonstrated that a short term (21 days) dietary exposure of adult zebrafish to triclosan ( $100 \mu \mathrm{g} \mathrm{g}^{-1}$ fish per day) affected the morphology of the thyroid tissue and upregulated the expression 

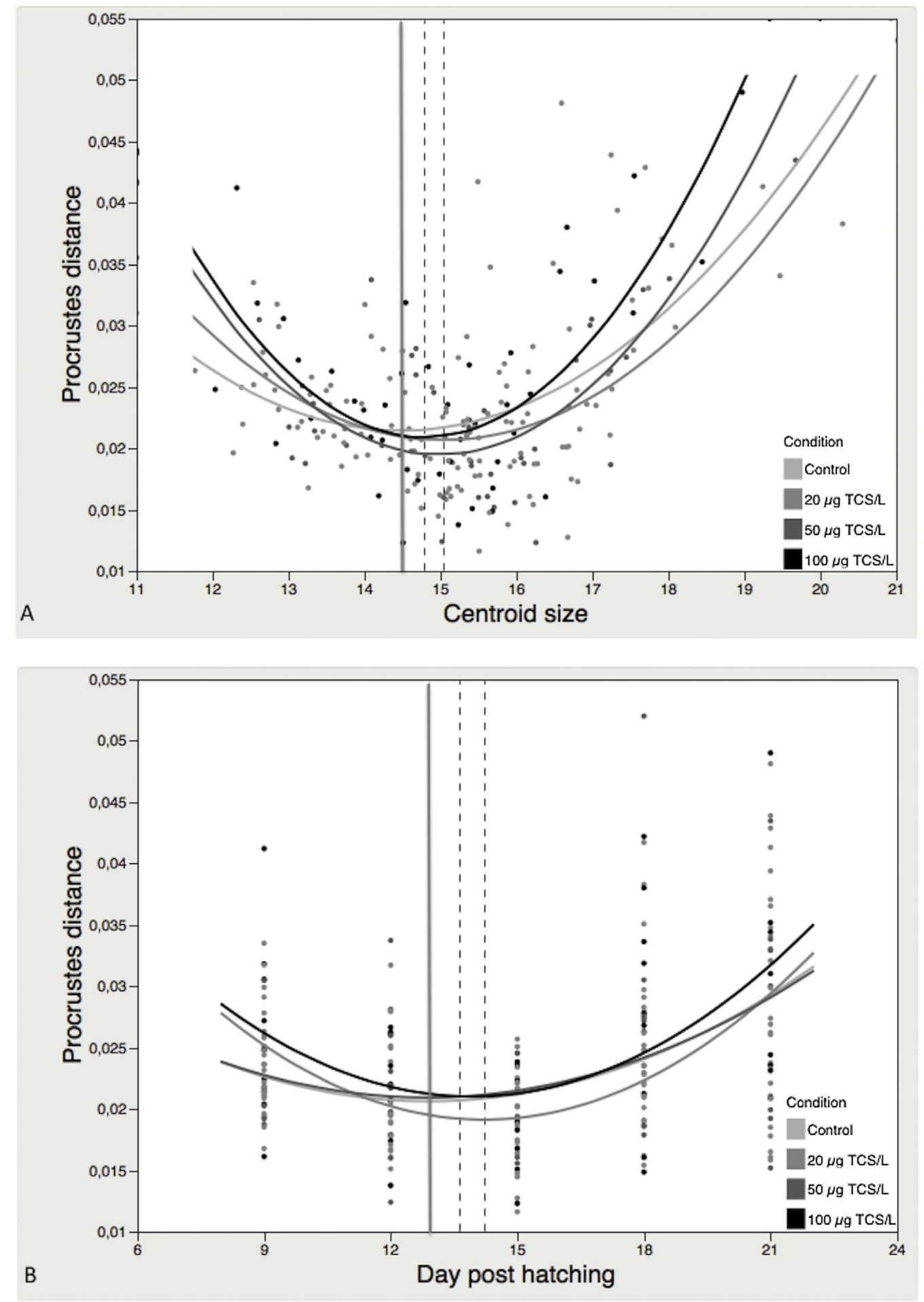

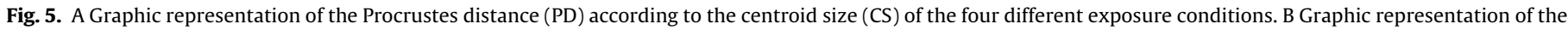

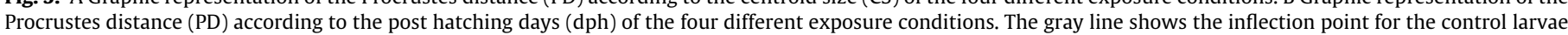
and the black dotted lines show the inflection points of the trendlines for triclosan-exposed groups.

of thyroid-stimulating hormone (TSH) and sodium-iodide transporter (Pinto et al., 2013). This will clearly affect T4 synthesis and secretion. Studies on other aquatic vertebrates such as frogs have shown that environmentally relevant levels of triclosan can disrupt the expression profile of thyroid hormone receptors (Veldhoen et al., 2006) and the expression of TR $\alpha$ (Fort et al., 2009). Stud- ies on rats showed no significant effects of triclosan on thyroid histology (Zorrilla et al., 2009) or thyroid mass (Axelstad et al., 2013) but they revealed a consistent dose-dependent decline in serum T4 whereas the decrease in serum T3 was less pronounced (Axelstad et al., 2013; Crofton et al., 2007; Paul et al., 2009; Stoker et al., 2010; Zorrilla et al., 2009). These studies suggest that the 
brain-pituitary-thyroid axis that regulates T4 biosynthesis and secretion is not affected by triclosan exposure.

It was therefore speculated that triclosan-induced hypothyroxinemia was likely due to an increased glucuronidation and sulfation of thyroid hormones. The first study to indicate that triclosan is capable of inhibiting sulfation of thyroid hormones was performed by Schuur et al., 1998, who studied the in vitro inhibition of diiodothyronine (T2) sulfotransferase activity using rat liver cytosol (Schuur et al., 1998). Studies on rats gavaged with triclosan revealed an increased T4-glucuronidation activity (Paul et al., 2009; Zorrilla et al., 2009). The contribution of other mechanisms of triclosaninduced thyroid hormone deficiency, such as impaired deiodinase activity or competitive binding to thyroid hormone serum proteins, have been even less explored (Butt et al., 2011). Currently, it is difficult to suggest underlying mechanisms of triclosan effects on the thyroid system in C. variegatus. A disturbed conversion of T4 to T3 would lead to increased T4 levels while preventing the formation of a T3 peak. Future studies are needed to confirm these suspected mechanisms of action.

\subsection{Effect of triclosan on development and pattern of ontogenetic shape variation}

Metamorphosis is a developmental period of critical importance for vertebrates, which it is mainly orchestrated by THs (Laudet, 2011). Consequently, the disruption caused by triclosan exposure could have profound effects on physiology, morphology and development (Power et al., 2001; Yamano, 2005). Very few studies have explored the impact of triclosan exposure on morphological variation over ontogeny (Oliveira et al., 2009). Fort et al. (2009) found no impact of triclosan exposure on Xenopus laevis metamorphosis, whereas Veldhoen et al. (2006) showed the opposite. In teleosts, some studies have reported spinal deformity or oral jaws blocked in larvae exposed to sublethal triclosan concentrations (Nassef et al., 2010; Oliveira et al., 2009; Orvos et al., 2002). These observations are not supported by our results. Indeed, in our experiments (including exposure up to $100 \mu \mathrm{g}$ triclosan $\mathrm{L}^{-1}$ ) we did not observe any abnormal modifications of the overall body shape. Moreover, no morphological repatterning was found, as the ontogenetic trajectories, i.e. the relation size vs. shape or time vs. shape, did not differ among treatment groups (Supplementary material Table 5).

Our results demonstrate a developmental delay in triclosanexposed C. variegatus. Triclosan-exposed fish remain longer in their larval stage before moving on to a second phase of development, during which a many shape changes occurs (Fig. 5). Highlighted by the study of ontogenetic vector lengths, larvae exposed to $100 \mu \mathrm{g}$ triclosan $\mathrm{L}^{-1}$ displayed less shape variation between 9 and $21 \mathrm{dph}$ than in other conditions. We hypothesize that the endocrine disruption caused by triclosan exposure prohibits the starting signal for metamorphosis. Our hypothesis is supported by the larger body weight of 15 -dph larvae exposed to $100 \mu \mathrm{g}$ triclosan $\mathrm{L}^{-1}$. Similarly, thyroidectomy or the injection of inhibitors of thyroid hormones prevents metamorphosis in Rana pipiens and forms giant tadpoles (Allen, 1918; Dodd and Dodd, 1976). Metamorphosis arrest was also observed in Japanese flounder (Paralichthys olivaceus) treated with goitrogens that inhibit the production of thyroid hormones, resulting in oversized pelagic larvae (Inui et al., 1995).

The transition from larva to juvenile is regulated by THs (Paris and Laudet, 2008; Power et al., 2001), which coordinate the morphological and physiological changes of several organs. The absence of the T3 peak in the triclosan-exposed larvae emphasizes the notion that the starting signal for metamorphosis was inadequate. It is possible that other hormones, which are involved in the metamorphosis such as the IGF (insulin-like growth factor) (McMenamin and Parichy, 2013), initiate the metamorphosis in exposed larvae. Thus, these exposed larvae enter their metamorphosis later despite the absence of a thyroid-mediated signal.

Sheepshead minnow remains longer in a larval state while continuing to grow and gain weight. Metamorphosis, a pervasive morphological remodelling phase, is an energy-consuming process as evidenced by respirometry techniques (Lallemand et al., 2014). Indeed, we have shown that $C$. variegatus larvae from control groups have a metabolism nearly two times higher than triclosan-exposed larvae at $15 \mathrm{dph}$ (Lallemand et al., 2014). While the control larvae invest energy to achieve metamorphic transformations, triclosanexposed larvae in maintaining a basic metabolic rate; they remain in a larval stage at this time.

Delayed metamorphosis may result in latent effects on juvenile or adult populations (Pechenik, 2006). Metamorphosis presents in an ecological context a period of increased vulnerability, which is often associated with the acquisition of a new habitat (Osse and Van den Boogaart, 1997). Indeed, the mortality operating during pre-juvenile stages greatly determined the year-class strength of feral flatfish populations (van der Veer and Nash, 2001). Some tropical reef fish can delay their metamorphosis (Cowen, 1991; Jenkins and May, 1994; McCormick, 1999; Victor, 1986), without direct evidence for any effect on subsequent juvenile or adult fitness (Cowen, 1991; Victor, 1986). However, a delayed metamorphosis may affect larval growth and their physiological conditions which are directly related to juvenile survival (Searcy and Sponaugle, 2001; Shima and Findlay, 2002). In various marine fishes, metamorphosis occurs in parallel with habitat shifts (Lecchini and Galzin, 2005). A delay of development may produce less efficient overall body shapes for active swimming during the period of habitat selection, ultimately impacting the success of settlement. The extent to which those latent effects alter ecological outcomes in natural populations and the mechanisms through which they are mediated need to be explored in future studies (Pechenik, 2006).

To conclude, we show that triclosan exposure affects the pattern of thyroid hormone concentrations during the early development of $C$. variegatus. In our experiments, Triclosan exposure produced a developmental delay in $C$. variegatus: delay of hatching time (6-13 h) and delay of overall body shape changes (18-32 h). Triclosan exposure resulted thus in a global delay of 24 to $45 \mathrm{~h}$, equivalent to $4-7 \%$ prolongation of the developmental time in $C$. variegatus. On the other hand, no effect on hatching success, no malformation and no morphological repatterning was observed. We conclude that the triclosan-induced thyroid disruption affects the timing of metamorphosis. The costs of delayed metamorphosis can lead to reduction of juvenile fitness and could be a determining factor in the outcome of competitive interactions.

\section{Acknowledgements}

Schnitzler, J. and Frédérich, B. are postdoctoral researchers at F.R.S-FNRS (Fonds de la recherche scientifique). Das, K. is F.R.SFNRS Research Associate. This study was partly funded by FRFC $\mathrm{n}^{\circ}$ 2.4635.11 (F.R.S-FNRS). AFFISH-RC is the Applied and Fundamental Fish Research Centre of the University of Liège. This is a MARE publication $n^{\circ} 340$.

\section{Appendix A. Supplementary data}

Supplementary data associated with this article can be found, in the online version, at http://dx.doi.org/10.1016/j.aquatox.2016.10. 019.

\section{References}

Allen, B.M., 1918. The results of thyroid removal in the larvae of Rana pipiens. J Exp. Zool. 24, 499-519. 
Axelstad, M., Boberg, J., Vinggaard, A.M., Christiansen, S., Hass, U., 2013. Triclosan exposure reduces thyroxine levels in pregnant and lactating rat dams and in directly exposed offspring. Food Chem. Toxicol. 59, 534-540.

Bedoux, G., Roig, B., Thomas, O., Dupont, V., Le Bot, B., 2011. Occurrence and toxicity of antimicrobial triclosan and by-products in the environment. Environ. Sci. Pollut. Res., 1-22.

Bernier, N.J., Flik, G., Klaren, P.H., 2009. Regulation and contribution of the corticotropic, melanotropic and thyrotropic axes to the stress response in fishes. Fish Physiol. 28, 235-311.

Blanton, M.L., Specker, J.L., 2007. The Hypothalamic-Pituitary-Thyroid (HPT) axis in fish and its role in fish development and reproduction. Crit. Rev. Toxicol. 37. 97-115.

Boas, M., Feldt-Rasmussen, U., Skakkebaek, N.E., Main, K.M., 2006. Environmental chemicals and thyroid function. Eur. J. Endocrinol. 154, 599-611.

Bookstein, F.L., 1996. Combining the tools of geometric morphometrics Advances in morphometrics. Springer, pp. 131-151

Bookstein, F.L., 1997. Morphometric Tools for Landmark Data: Geometry and Biology. University Press, Cambridge.

Brännäs, E., 1987. Influence of photoperiod and temperature on hatching and emergence of Baltic salmon (Salmo salar L.). Can. J. Zool. 65, 1503-1508.

Brown, S.B., Adams, B.A., Cyr, D.G., Eales, J.G., 2004. Contaminant effects on the teleost fish thyroid. Environ. Toxicol. Chem. 23, 1680-1701.

Butt, C.M., Wang, D., Stapleton, H.M., 2011. Halogenated phenolic contaminants inhibit the in vitro activity of the thyroid regulating deiodinases in human liver. Toxicol. Sci. 124, 339-347.

Chang, J., Wang, M., Gui, W., Zhao, Y., Yu, L., Zhu, G., 2012. Changes in thyroid hormone levels during zebrafish development. Zoolog. Sci. 29, 181-184.

Cowen, R.K., 1991. Variation in the planktonic larval duration of the temperate wrasse Semicossyphus pulcher. Mar. Ecol. Prog. Ser. 69, 9-15.

Crane, H.M., Pickford, D.B., Hutchinson, T.H., Brown, J.A., 2004. Developmental changes of thyroid hormones in the fathead minnow, Pimephales promelas. Gen. Comp. Endocrinol. 139, 55-60.

Cripe, G.M., Hemmer, B.L., Goodman, L.R., Vennari, J.C., 2009. Development of a methodology for successful multigeneration life-cycle testing of the estuarine sheepshead minnow, Cyprinodon variegatus. Arch. Environ. Contam. Toxicol. 56, 500-508

Crofton, K.M., Paul, K.B., DeVito, M.J., Hedge, J.M., 2007. Short-term in vivo exposure to the water contaminant triclosan: evidence for disruption of thyroxine. Environ. Toxicol. Pharmacol. 24, 194-197.

Dann, A.B., Hontela, A., 2011. Triclosan: environmental exposure, toxicity and mechanisms of action. J. Appl. Toxicol. 31, 285.

Dodd, M., Dodd, J., 1976. The biology of metamorphosis. Physiol. Amphibia 3, 467-599.

Dufour, S., Rousseau, K., Kapoor, B.G., 2012. Metamorphosis in Fish. CRC Press.

Eales, J.G., Brown, S.B., 1993. Measurement and regulation of thyroidal status in teleost fish. Rev. Fish Biol. Fish. 3, 299-347.

Fang, J.-L., Stingley, R.L., Beland, F.A., Harrouk, W., Lumpkins, D.L., Howard, P., 2010. Occurrence, efficacy, metabolism, and toxicity of triclosan. J. Environ. Sci. Health Part C Environ. Carcinog. Ecotoxicol. Rev. 28, 147-171.

Fort, D.J., Rogers, R.L., Gorsuch, J.W., Navarro, L.T., Peter, R., Plautz, J.R., 2009 Triclosan and anuran metamorphosis: no effect on thyroid-mediated metamorphosis in Xenopus laevis. Toxicol. Sci. 113, 392-400.

Hallare, A., Nagel, K., Köhler, H.-R., Triebskorn, R., 2006. Comparative embryotoxicity and proteotoxicity of three carrier solvents to zebrafish (Danio rerio) embryos. Ecotoxicol. Environ. Saf. 63, 378-388.

Inui, Y., Yamano, K., Miwa, S., 1995. The role of thyroid hormone in tissue development in metamorphosing flounder. Aquaculture 135, 87-98.

Ishibashi, H., Matsumura, N., Hirano, M., Matsuoka, M., Shiratsuchi, H., Ishibashi, Y. Takao, Y., Arizono, K., 2004. Effects of triclosan on the early life stages and reproduction of medaka Oryzias latipes and induction of hepatic vitellogenin. Aquat. Toxicol. 67, 167-179.

Jenkins, G.P., May, H., 1994. Variation in settlement and larval duration of king george whiting sillaginodes punctata (Sillaginidae), in swan bay victoria, Australia. Bull. Mar. Sci. 54, 281-296

Johns, S.M., Kane, M.D., Denslow, N.D., Watanabe, K.H., Orlando, E.F., Villeneuve, D.L., Ankley, G.T., Sepulveda, M.S., 2009. Characterization of ontogenetic changes in gene expression in the fathead minnow (Pimephales promelas). Environ. Toxicol. Chem. 28, 873-880.

Kawakami, Y., Tanda, M., Adachi, S., Yamauchi, K., 2003. Characterization of thyroid hormone receptor $\alpha$ and $\beta$ in the metamorphosing Japanese conger eel, Conger myriaster. Gen. Comp. Endocrinol. 132, 321-332.

Klaren, P.H.M., Wunderink, Y.S., Yufera, M., Mancera, J.M., Flik, G., 2008. The thyroid gland and thyroid hormones in Senegalese sole (Solea senegalensis) during early development and metamorphosis. Gen. Comp. Endocrinol. 155, 686-694.

Klingenberg, C.P., McIntyre, G.S., 1998. Geometric morphometrics of developmental instability: analyzing patterns of fluctuating asymmetry with Procrustes methods. Evolution, 1363-1375

Kolpin, D.W., Furlong, E.T., Meyer, M.T., Thurman, E.M., Zaugg, S.D., Barber, L.B., Buxton, H.T., 2002. Pharmaceuticals, hormones, and other organic wastewater contaminants in U.S. streams: 1999-2000: A national reconnaissance. Environ. Sci. Technol. 36, 1202-1211.

Lallemand, L., Voisin, A.-S., Darchambeau, F., Das, K., Schnitzler, J., 2014. The effects of Triclosan on the metabolism of developing Sheepshead minnow (Cyprinodon variegatus) larvae. ZOOLOGY 2014-Congrès Benelux de Zoologie.

Laudet, V., 2011. The origins and evolution of vertebrate metamorphosis. Curr. Biol. 21, R726-R737.
Lawing, A.M., Polly, P.D., 2010. Geometric morphometrics: recent applications to the study of evolution and development. J. Zool. 280, 1-7.

Leatherland, J.F., 1982. Environmental physiology of the teleostean thyroid gland: a review. Environ. Biol. Fishes 7, 83-110.

Lecchini, D., Galzin, R., 2005. Spatial repartition and ontogenetic shifts in habitat use by coral reef fishes (Moorea, French Polynesia). Mar. Biol. 147, 47-58.

McCormick, M.I., 1999. Delayed metamorphosis of a tropical reef fish (Acanthurus triostegus): a field experiment. Mar. Ecol. Prog. Ser. 176, 25-38.

McMenamin, S.K., Parichy, D.M., 2013. Metamorphosis in teleosts. Curr. Top. Dev. Biol. 103, 127-165.

Nassef, M., Kim, S.G., Seki, M., Kang, I.J., Hano, T., Shimasaki, Y., Oshima, Y., 2010. In ovo nanoinjection of triclosan, diclofenac and carbamazepine affects embryonic development of medaka fish (Oryzias latipes). Chemosphere 79, 966-973.

OECD, 2013. OECD guidelines for testing of chemicals: fish, early-life stage toxicity test. OECD Publ.

Oliveira, R., Domingues, I., Grisolia, C.K., Soares, A.M.V.M., 2009. Effects of triclosan on zebrafish early-life stages and adults. Environ. Sci. Pollut. Res. 16, 679-688.

Orvos, D.R., Versteeg, D.J., Inauen, J., Capdevielle, M., Rothenstein, A., Cunningham, V., 2002. Aquatic toxicity of triclosan. Environ. Toxicol. Chem. 21, 1338-1349.

Osse, J., Van den Boogaart, J., 1997. Size of flatfish larvae at transformation, functional demands and historical constraints. J. Sea Res. 37, 229-239.

Paris, M., Laudet, V., 2008. The history of a developmental stage: metamorphosis in chordates. Genesis 46, 657-672.

Paul, K.B., Hedge, J.M., Devito, M.J., Crofton, K.M., 2009. Short-term exposure to triclosan decreases thyroxine in vivo via upregulation of hepatic catabolism in young long-evans rats. Toxicol. Sci. 113, 367-379.

Pechenik, J.A., 2006. Larval experience and latent effects-metamorphosis is not a new beginning. Integr. Comp. Biol. 46, 323-333.

Pinto, P.I., Guerreiro, E.M., Power, D.M., 2013. Triclosan interferes with the thyroid axis in the zebrafish (Danio rerio). Toxicol. Res. 2, 60-69.

Power, D.M., Llewellyn, L., Faustino, M., Nowell, M.A., Björnsson, B.T., Einarsdottir, I.E., Canario, A.V.M., Sweeney, G.E., 2001. Thyroid hormones in growth and development of fish. Comp. Biochem. Physiol. Part C: Toxicol. Pharmacol. 130, 447-459.

R Development Core Team, 2014. R: A Language and Environment for Statistical Computing R Foundation for Statistical Computing. R Foundation for Statistical Computing, Vienna, Austria.

Rohlf, F.J., Marcus, L.F., 1993. A revolution morphometrics. Trends Ecol. Evol. 8 , 129-132.

Rohlf, F.J., Slice, D., 1990. Extensions of the Procrustes method for the optima superimposition of landmarks. Syst. Biol. 39, 40-59.

Schnitzler, J.G., Klaren, P.H.M., Mariavelle, E., Das, K., 2015. The thyroid gland and thyroid hormones in sheepshead minnow (Cyprinodon variegatus) during early development and metamorphosis. Fish. Physiol. Biochem. 42, 607-616.

Schnitzler, J.G., Dussenne, M., Frédérich, B., Das, K., 2016. Post-embryonic development of sheepshead minnow Cyprinodon variegatus: a staging tool based on externally visible anatomical traits. Ichthyol. Res. 64, 1-8.

Schuur, A.G., van Leeuwen-Bol, I., Jong, W.M., Bergman, Å., Coughtrie, M.W., Brouwer, A., Visser, T.J., 1998. In vitro inhibition of thyroid hormone sulfation by polychlorobiphenylols: isozyme specificity and inhibition kinetics. Toxicol. Sci. 45, 188-194.

Searcy, S.P., Sponaugle, S., 2001. Selective mortality during the larval-juvenile transition in two coral reef fishes. Ecology 82, 2452-2470.

Sheets, H., 2014. Regress8: calculation of regressions between shape variables and a dependant variable. Buffalo.

Shiao, J.-C., Wu, S.-M., Hwang, Y.-P., Wu, D.-P., Hwang, P.-P., 2008. Evaluation of thyroid-mediated otolith growth of larval and juvenile tilapia. J. Exp. Biol. 211, 1919-1926.

Shima, J.S., Findlay, A.M., 2002. Pelagic larval growth rate impacts benthic settlement and survival of a temperate reef fish. Mar. Ecol. Prog. Ser. 235 303-309.

Stoker, T.E., Gibson, E.K., Zorrilla, L.M., 2010. Triclosan exposure modulates estrogen-dependent responses in the female Wistar rat. Toxicol. Sci. 117 45-53.

Szisch, V., Papandroulakis, N., Fanouraki, E., Pavlidis, M., 2005. Ontogeny of the thyroid hormones and cortisol in the gilthead sea bream, Sparus aurata. Gen. Comp. Endocrinol. 142, 186-192.

Tagawa, M., Hirano, T., 1987. Presence of thyroxine in eggs and changes in its content during early development of chum salmon, Oncorhynchus keta. Gen. Comp. Endocrinol. 68, 129-135.

Veldhoen, N., Skirrow, R.C., Osachoff, H., Wigmore, H., Clapson, D.J., Gunderson, M.P., Van Aggelen, G., Helbing, C.C., 2006. The bactericidal agent triclosan modulates thyroid hormone-associated gene expression and disrupts postembryonic anuran development. Aquat. Toxicol. 80, 217-227.

Victor, B.C., 1986. Delayed metamorphosis with reduced larval growth in aCora reef fish (Thalassoma bifasciatum). Can. J. Fish. Aquat.Sci. 43, 1208-1213.

Villamizar, N., Blanco-Vives, B., Oliveira, C., Dinis, M.T., Di Rosa, V., Negrini, P., Bertolucci, C., Sánchez-Vázquez, F.J., 2013. Circadian rhythms of embryonic development and hatching in fish: a comparative study of Zebrafish (diurnal), Senegalese sole (nocturnal), and Somalian cavefish (blind). Chronobiol. Int. 30, 889-900.

Webster, M., Zelditch, M.L., 2005. Evolutionary modifications of ontogeny: heterochrony and beyond. Paleobiology 31, 354-372.

Yamano, K., 2005. The role of thyroid hormone in fish development with reference to aquaculture. JARQ-Japan Agricult. Res. Q. 39, 161-168. 
Zelditch, M.L., Lundrigan, B.L., Garland, T., 2004. Developmental regulation of skull morphology: I. Ontogenetic dynamics of variance. Evol. Dev.t 6, 194-206.

Zelditch, M.L., Swiderski, D.L., Sheets, H.D., 2012. Geometric Morphometrics for Biologists: a Primer. Academic Press.

Zoeller, R.T., Tan, S.T., Tyl, R.W., 2007. General background on the

Hypothalamic-Pituitary-Thyroid (HPT) axis. Crit. Rev. Toxicol. 37, 11-53.

Zorrilla, L.M., Gibson, E.K., Jeffay, S.C. Crofton, K.M., Setzer, W.R Cooper, R.

Stoker, T.E., 2009. The effects of triclosan on puberty and thyroid hormones in male Wistar rats. Toxicol. Sci. 107, 56-64. de Jesus, E.G.T., Hirano, T., 1992. Changes in whole body concentrations of cortisol, thyroid hormones, and sex steroids during early development of the chum salmon, Oncorhynchus keta. Gen. Comp. Endocrinol. 85, 55-61.

van der Veer, H.W., Nash, R.D., 2001. The 1999 Flatfish Symposium: where to go from now? J. Sea Res. 45, 325-328. 